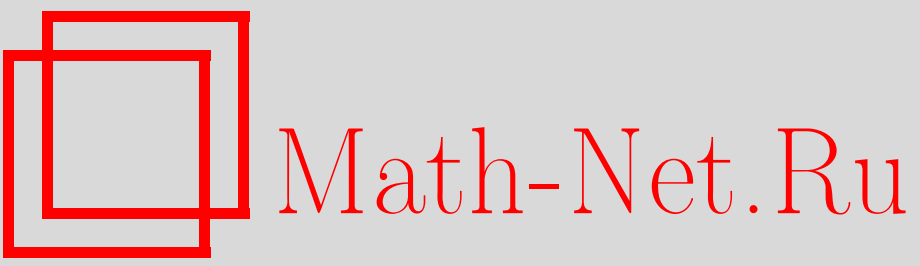

С. В. Зеленов, Теорема плотности Зельмановича в градуированном случае, УМH, 2001, том 56, выпуск 3, 167-168

DOI: https://doi.org/10.4213/rm405

Использование Общероссийского математического портала Math-Net.Ru подразумевает, что вы прочитали и согласны с пользовательским соглашением

http://www . mathnet.ru/rus/agreement

Параметры загрузки:

IP : 3.85 .73 .92

26 апреля 2023 г., 17:39:31 


\title{
ТЕОРЕМА ПЛОТНОСТИ ЗЕЛЬМАНОВИЧА В ГРАДУИРОВАННОМ СЛУЧАЕ
}

\author{
С. В. ЗЕлЕНОВ
}

В работе вводятся понятия градуированного критически-сжимаемого модуля, квази-инъективной оболочки, изучается их строение и доказывается теорема плотности для градуированного слабо примитивного кольца.

Пусть $H$ и $G$ - две полугруппы. Множество $A$ назьвается $(H, G)$-полигоном, если $H$ действует на $A$ слева, а $G$ - справа, причем если $a \in A, h \in H, g \in G$, то $(h a) g=h(a g)$. Пусть дополнительно для всяких $a, a^{\prime} \in A, g, g^{\prime} \in G, h, h^{\prime} \in H$ выполняются свойства: $a g=a g^{\prime} \Rightarrow g=g^{\prime}$; $a g=a^{\prime} g \Rightarrow a=a^{\prime} ; h a=h^{\prime} a \Rightarrow h=h^{\prime} ; h a=h a^{\prime} \Rightarrow a=a^{\prime}$.

Везде далее $R$ - градуированное по $G$ ассоциативное кольцо без единицы, $M$ - градуированный по $A$ правый $R$-модуль.

Назовем градуированньй модуль сжимаемым, если он вкладывается однородным мономорфизмом в каждый свой ненулевой градуированный подмодул; если, кроме того, он не может быть вложен ни в какой свой собственный градуированньй фактор-модуль, назовем его критичесжи-сжимаемым. Назовем градуированный модуль униформныцм, если любая пара его ненулевых градуированных подмодулей имеет ненулевое пересечение. Частичным эндоморфизмом градуированного модуля $M$ назовем гомоморфизм $N \rightarrow M$, где $N$ - градуированный подмодуль в $M$.

ПрЕДЛОЖЕНИЕ 1. Для сжимаемого градуированного модуля $M$ әквивалентно: (1) $M$ критически-сжимаем; (2) каждый его ненулевой однородный частичный эндоморфизм является мономорфизмом. Кроме того, любой градуированный модуль, удовлетворяющий условию (2), униформен.

Модуль, удовлетворяющий условию (2), назовем моноформным.

Градуированньй модуль назовем квази-инвективньцм, если каждый его градуированньй частичньй эндоморфизм продолжается до градуированного эндоморфизма всего модуля. Каждый модуль $M$ может быть вложен в наименьший градуированный квази-инъективный модуль $\bar{M}$, которьй назовем его квази-инбективной оболочкой.

Пусть $\widehat{M}$ - инъективная оболочка модуля $M, \Lambda=\operatorname{END}(\widehat{M})$.

ПРедЛОЖЕНИЕ 2. (1) $\Lambda M$ является пересечением всех градуированных квази-индективных подмодулей модуля $\widehat{M}$, содержащих $M$; (2) $\Lambda M$ - градуированный квази-индективный модуль; (3) градуированный модуль $М$ квази-инбективен тогда и только тогда, когда $M=\Lambda M$.

СледСтвиЕ. (1) $\bar{M}=\Lambda M ;(2) \bar{M}=\Delta M$, әде $\Delta=\operatorname{END}\left(\bar{M}_{R}\right)$.

ПРедЛОЖЕНИЕ 3. (1) Если $M_{R}$ - градуированный моноформный модуль, то однородные әлементы из $D=\operatorname{END}\left(M_{R}\right)$ однозначно продолжаются до әлементов из $\Delta$, причем $\Delta$ оказывается градуированным кольцом с делением. (2) Eсли $M_{R}$ критически-сжимаем, то $D$ - градуированная правая область Оре с кольчом частных $\Delta$.

Назовем слабо-примитивным градуированное кольцо, обладающее точным критическисжимаемым градуированным модулем. Назовем $R$-решеткой тройку $\left(\Delta,{ }_{\Delta} V_{R}, M_{R}\right)$, где $V-$ $A$-градуированньй $(\Delta, R)$-бимодуль, $\Delta-H$-градуированное кольцо с делением, $\Delta M=V$, $R$ действует точно на $M$.

ТЕОРемА. Для градуированного кольца $R$ әквивалентны условия:

(1) $R$ слабо-примитивно;

(2) существует такая $R$-решетка $\left(\Delta,{ }_{\Delta} V_{R}, M_{R}\right)$, что для данных $\Delta$-независимьх әлементов $v_{1}, \ldots, v_{k} \in h(V)$ существ ует такой $0 \neq a \in h(\Delta)$, что для любых $n_{1}, \ldots, n_{k}$ $\in M$ найдется $r \in R$ с $а n_{i}=v_{i} r \in M$ для всех $i=1, \ldots, k$, причем, если $k=1 u$ $n_{1} \in h(M)$, mo $r \in h(R)$; 
(3) существует такая $R$-решетка $\left(\Delta,{ }_{\Delta} V_{R}, M_{R}\right)$, что для данных конечномерных градуированных $\Delta$-подпространств $U$ и $U^{\prime}=\sum_{i=1}^{k} \Delta m_{i}$ модуля $V$, где $m_{1}, \ldots, m_{k} \in$ $h(M)$, и $\tau \in \operatorname{END}(\Delta V)$ существуют такие $r, s \in R$, ито $\left.(\tau r-s)\right|_{U}=0$ и $\left.r\right|_{U^{\prime}}$ является градуированным автоморфизмом, причем если $U=\Delta m u U^{\prime}=\Delta m^{\prime} n p u m, m^{\prime} \in h(M)$ u $m \tau \in h(V)$, mo $s \in h(R)$.

ДоКАЗАТЕЛЬСтво. (1) $\Rightarrow(2)$ : предложение 1 , следствие и предложение 3 позволяют в качестве $R$-решетки выбрать $\left(\Delta,{ }_{\Delta} \bar{M}_{R}, M_{R}\right)$; для поиска нужного эндоморфизма $a$ применяется теорема слабой плотности (см. [1]).

$(2) \Rightarrow(3)$ - аналогично неградуированному случаю (см. [2]); заметим, что однородность $a$ в условии (2) гарантирует его обратимость, которая требуется при доказательстве.

$(3) \Rightarrow(1)$ : критически-сжимаемым оказьвается модуль $\{m r+m q \mid q \in \mathbb{Q}\}$ для $0 \neq m \in$ $h(M)$; при этом однородность $s$ в "одномерном" условии (3) гарантирует однородность мономорфизма, требующуюся в определении сжимаемости.

Пользуюсь случаем выразить благодарность А. В. Михалёву за постановку задач и внимание к работе.

\section{СПИСОК ЛИТЕРАТУРЫ}

[1] С. В. Зеленов // Труды 6-х математических чтений МГСУ. Москва, 1999. С. 107-110. [2] J. Zelmanowitz // Comm. Algebra. 1981. V. 9. № 1. P. 23-45.

Московский государственный университет им. М. В. Ломоносова

E-mail: szelenov@rambler.ru
Принято редколлегией

29.03.2001 